\title{
Mate Retention Tactics Decline with Age of Iranian Men
}

\author{
Farid Pazhoohi ${ }^{1}$ - Alaeddin Sayahian Jahromi ${ }^{2} \cdot$ James Francis Doyle $^{3}$
}

Published online: 8 March 2016

(C) Springer International Publishing 2016

\begin{abstract}
This study tested the hypothesis that the frequency of non-Western male's use of mate retention tactics decreases with age. Results from 244 Iranian female partner's selfreports of their Iranian male mate's mate retention tactics are presented. It is shown that the reported frequency of mate retention tactics is not associated with the female participant's age, relationship status, or use of oral contraceptives and that the reported frequency of mate retention tactics decreases as these men age. Additionally, analysis showed that the age difference between the Iranian women respondents and their male partners did not result in more frequent use of mate retention tactics; counterintuitively, age difference was negatively correlated with mate retention tactics. Results, limitations, and the role of testosterone supported by the outcome of this study are discussed.
\end{abstract}

Keywords Aging $\cdot$ Testosterone $\cdot$ Mate retention

To our knowledge, there has been no investigation of the relationship between frequency of mate retention tactic use by men and their age or between male mate retention tactic use and age difference between partners. For the purposes of this study, Iranian women were surveyed about their Iranian male partners to confirm that (1) frequency of mate retention tactics used by men is reported to decrease as men age, (2)

Farid Pazhoohi

pazhoohi@gmail.com

\footnotetext{
Shiraz, Iran

Zarghan Branch, Islamic Azad University, Zarghan, Iran

Stillwater, MN, USA
}

frequency of mate retention tactics lessens with female partner's age, (3) age difference between partners increases mate retention, (4) contraceptive pill usage by women affects mate retention behaviors in their partners, and (5) relationship status ("in a relationship," "engaged," or "married") increases or decreases the frequency of the reported mate retention tactics.

Historically, androcentrism and extended patriarchy is the main characteristic of the Iranian family structure (Aghajanian and Thompson 2013; Friedl 1994). In a culture such as Iran, any inclination toward divorce and marital dissolution has been strongly prohibited by parents and elders of the extended family as marriage has been considered the ideal structure of family and societal morality (Aghajanian and Thompson 2013; McDonald 1994). By tradition, consanguineous marriage has been preferred in Iran and accounts for approximately $40 \%$ of unions. This type of matrimony can be understood in relation to arranged marriages in which family support and control over individual's mate choices have remained greatly influential to the present time. Iranian parents first look to their own families to locate possible spouses for their children (Abbasi-Shavazi et al. 2008). However, in recent decades, the demand for higher education, the age of first marriage, as well as divorce rates are increasing while fertility rates decrease due to the influences of economic development and globalization (Abbasi-Shavazi et al. 2009; Torabi and Baschieri 2010). Iran is among the countries in which premarital sex continues to be strongly discouraged and chastity is highly valued (Buss 1989). Historically, Iranians have endorsed cultural practices in which men guard their wives and female relatives more rigorously than their Western counterparts (Pazhoohi and Hosseinchari 2014).

Physical attractiveness influences mate selection across cultures (Buss 1989), and youthfulness of women is associated with their future reproductive value and present fertility (Kenrick and Keefe 1992; Symons 1979). Men attribute 
importance to youthful features in females such as large eyes, small nose, higher pitched voice, and full lips and perceive these neotenous features as attractive (Jones 1995; Perrett et al. 1998; Puts 2010; Puts et al. 2011). More feminine women report more frequently being guarded by their partners than less feminine and less attractive women (Buss and Shackelford 1997; Haselton and Gangestad 2006). Men perform greater retention efforts to guard their attractive partners (Goetz et al. 2005), and women's age is negatively associated with degree of mate affiliative behaviors, e.g., touching in a Russian sample (Dillon et al. 2014). If mate retention tactics are related to physical attractiveness and physical attractiveness is a proxy of fertility and reproductive value, the prediction that mate retention efforts of men would decrease as their partners age could be explained by decreasing physical attractiveness as indicators of lowered reproductive value. However, age difference, as a measure of how many years younger a woman is than her male partner, should tend to increase mate retention tactics if attractivenessas a proxy for fertility and reproductive potential-is the primary reason for employing mate retention tactics. We propose that declining testosterone is related to reduced use of Iranian men's mate retention tactics.

Men undergo age-related andropause which is associated with decline in ability to attract mates, compete with conspecifics, decreased sexual motivation, and energy availability (Bribiescas 2006). Therefore, one might expect selection to have shaped males' efforts in mate acquisition and retention to peak when female cohorts are maximally fertile and decrease as testosterone levels and female fertility decline as they age. Levels of testosterone are associated with dominance, social status, and marital relationships, and it has been suggested that "when stress is low, higher testosterone men may devote more attention to their spouses, take the initiative in expressing positive interaction, and make a greater overall investment in the relationship" (Booth et al. 2006). Overall, testosterone promotes mating effort through the triggering of physiological and behavioral secondary sex traits to facilitate mate pursuit, same-sex competition, and the display of courtship behaviors (Ellison 2009). Circulating testosterone level is associated with male sexual behaviors (Fales et al. 2014) such as mate guarding and pair bonding. Bribiescas (2006) suggested like women's menopause, men also undergo an agerelated andropause which is associated with decreased ability to attract mates, compete with conspecifics, decreased sexual motivation, energy availability, and a compromised ability to acquire resources resulting in "a form of male reproductive senescence that severely restricts male fitness at older ages." Men over 45 years report decreased sexual desire, sexual arousal, and activity (Schiavi et al. 1991). Both sexual activity and serum testosterone decrease with age in men (Ferrini and Barrett-Connor 1998; Tsitouras et al. 1982). In addition to this reduction in serum testosterone, the circadian testosterone rhythm is absent and impaired in healthy elderly men (Bremner et al. 1983). Furthermore, a man's increase in age is associated with increased odds of conception failure (de $\mathrm{La}$ Rochebrochard et al. 2006). Overall, testosterone level, sperm production, and quality decline with age (Alvergne et al. 2009; Ellison et al. 2002; Feldman et al. 2002; Harman et al. 2001; Nahoul and Roger 1990; Plas et al. 2000; Uchida et al. 2006); for review see Bribiescas (2006) and Muehlenbein and Flinn (2011). Considering age-dependent testosterone decrease and the association of testosterone with the intensity of mate guarding, it is posited that men show a lesser degree of mate retention behaviors as they age and increased age difference does not increase reported use of mate retention tactics. However, no previous study has investigated the association of age, age difference between partners, and mate retention tactics in human males.

\section{Method}

Participants An online survey was developed, and participants were recruited via advertisements posted on social networks (Facebook and Telegram Messenger). Overall, 366 individuals participated in the survey. After discarding those with incomplete answers and those under 18 years of age from all analyses, our analyses consisted of data from 244 Iranian women (mean age $=24.39, \mathrm{SD}=5.9$, ranging 18 to 50 years). Some participants dropped out, and it is suspected that some of these did so for personal or religious reasons, or lack of technological proficiency. The mean for women's partner age was 26.26 with SD of 6.05 , ranging from 18 to 52 years. The percentages of married, engaged, and in a relationship were $25.4,29.1$, and 45.5 , respectively.

Procedure At the beginning of the survey, participants were asked to provide their sex, age, their partner's age, their relationship status, and whether they are currently using contraceptive pills. They then completed the Mate Retention Inventory-Short Form (MRI-SF) (Buss et al. 2008; Shackelford et al. 2005) where women rated their partner's behavior. The inventory measures performance frequencies of mate retention behaviors (how frequently the participant's partner performed the act within the past 1 year). The MRI-SF inventory consists of a 38-item self-report questionnaire on a 4-point Likert type scale with choices ranging from 0 as never performed this act to 3 as often performed this act. The total score for the scale yields a total score between 0 and 114, with higher scores indicating higher frequency of mate retention. The original English questionnaire was translated into Farsi for use with Iranian participants. The Farsi questionnaire was back-translated into English to check for accuracy. The Farsi version of the questionnaire can be obtained from the authors. 


\section{Results}

A linear regression was used to find relationships between mate retention score as dependent variable and (1) the age of the male partner and (2) the age of female participants as independent variables. A multiple regression analysis revealed that male partner's age was a significant predictor of the mate retention score $(\beta=-0.39, t=-2.48, p=0.014$; Fig. 1$)$. However, participant's age was not a predictor of the mate retention score $(\beta=0.18, t=1.13, p=0.261)$, though there was a highly significant positive correlation between participant's age and her partner's age, $r(242)=0.92, p<0.001$. The regression equation was significant, $F(2,241)=7.42$, $p<0.001$; Table 1 .

Additionally, there was a negative association between partners' age difference and mate retention score, meaning as the age difference between partners increased the mate retention score decreased, $r(242)=-0.14, p=0.035$.

An independent samples $t$ test was used to investigate the mate retention scores across two conditions of contraceptive usage and no usage. There was no significant effect of contraceptive use on mate retention score, $t(242)=-0.12, p=0.901$. Using analysis of variances, no difference in the mate retention score between the status of relationship was observed, $F(2,241)=1.15, p=0.319$.

\section{Discussion}

The results showed that as men age, mate retention tactic use declines: age of women's partners was negatively associated with their mate retention score. No significant relationship was observed between women's own age and their partner's use of mate retention. This finding suggests declining testosterone, rather than women's youthfulness alone, may mediate Iranian men's mate guarding. These results confirm that
Table 1 Summary of multiple regression analysis using enter method for variables predicting mate retention score $(n=244)$

\begin{tabular}{lrcc}
\hline Variable & \multicolumn{1}{l}{ B } & SE B & $\beta$ \\
\hline Participant age & 0.54 & 0.48 & 0.18 \\
Partner age & -1.13 & 0.46 & $-0.39^{*}$ \\
\hline
\end{tabular}

$R^{2}=0.06 ;$ adjusted $R^{2}=0.05$

${ }^{*} p<0.05$

partners' age difference and mate retention score are negatively associated: as the age difference between partners increased, mate retention score decreased. Moreover, no difference between relationship status was observed and no difference was found between those using contraceptive pills and those not using contraceptive pills.

Men report stronger attraction to femininity in women's faces when their testosterone level is high than when testosterone is low (Welling et al. 2008), and men's preferences for feminine female faces are highest among younger men and decline as men age (Marcinkowska et al. 2015), presumably due to decline in cycling testosterone levels. This study results showed a negative relationship between frequency of mate retention tactics used by Iranian men and their biological age as reported by their female partners, suggesting testosterone may also mediate the use of mate retention tactics as men age.

Shackelford et al. (2004) tested the effect of age on distress to cues of sexual infidelity across two samples of older people (mean age $=67$ years) and younger people (mean age $=20$ years). They showed that older men are less distressed than younger men by a partner's sexual infidelity, reasoning that post-reproductive women do not place their partner at risk of cuckoldry. However, the association of distress to sexual perception could be a function of lowered level of testosterone since higher levels of this hormone are associated with vigilance and violence by men toward their partners
Fig. 1 Linear regression showing the relationship between women's male partner age and partner's mate retention score

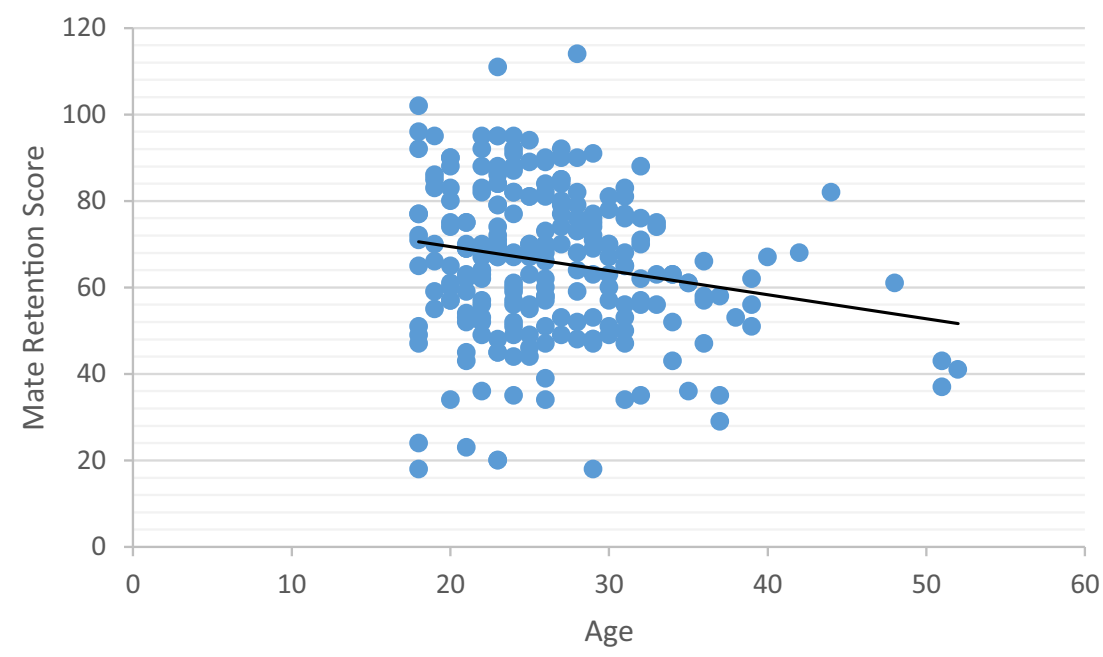


(Eisenegger et al. 2011; Fusani et al. 1997; Romero-Martínez et al. 2013a, b; Wirth and Schultheiss 2007). Moreover, the result of the current study shows a decline in men's mate retention behavior toward females between 18 and 50 years old (mean age $=24.39, \mathrm{SD}=5.9$ ) which includes both reproductive and post-reproductive age participants. Since the relationship between aging and overall mate retention score was negative but that age difference between partners did not increase mate retention tactic use, we suggest that testosterone level may affect mate retention over the life of mateships despite age differences. One mate retention category, resource display, was found to be positively correlated with men's age.One mate retention category, resource display, was found to be positively correlated with men's age (Table 2). It may be that the association found for this tactic is related to older men having, or being perceived to have, more resources than younger men. However, no information about actual assets or resources was collected.

American men's ratings of women's physical attractiveness are negatively associated with women's age but women's ratings of men's physical attractiveness are not similarly negatively correlated (Mathes et al. 1985). It is therefore interesting to note that Iranian men's mate retention tactics are negatively associated with age difference; although mate retention tactic use declines with age, it does not appear to be increased by greater age differences between older men and younger women. Thus, even though mate retention tactic use is reduced as men and women age and it is not increased by a wider age difference, lower testosterone may account for the lower frequency of mate retention behavior and not only women's physical attractiveness, at least in this Iranian sample. The average marriage age difference of husband and wife in Iran is 3.76 years old (Iran Statistical Center 2015). The average for this difference in our sample is 1.12 years old. Mean age of Iranian men and women is 29.7 and 30.0 years of old, respectively, which is older than the mean of age of participants of the current study. The mean age at first marriage for Iranian men and women is 26.7 and 23.4 , respectively.

This challenges the assumption that when the female partner is younger relative to her male partner, the male partner will employ more mate retention tactics to monopolize her higher reproductive value (jealousy induction was negatively correlated with age, see Table 2). This finding could be interpreted in the light of the cultural practice of arranged marriage in Iran in which families decide for their children who they may wed and consider marriage as a necessity even for their adult children (Abbasi-Shavazi et al. 2008). Close and extended familial interference by arranging marriage is the primary reported cause of divorce and marital dissatisfaction among Iranian couples (Barikani, Ebrahim, \& Navid 2012).

A relevant cultural phenomenon occurring in Iran is that some men engage in sexual behaviors with girlfriends while preferring to marry women who have not had premarital
Table 2 Pearson correlation between women's male partner age and partner's mate retention score

\begin{tabular}{lc}
\hline Tactic & Age \\
\hline Vigilance & $-0.12^{*}$ \\
Concealment of mate & -0.09 \\
Monopolization of time & -0.06 \\
Jealousy induction & $-0.16^{* *}$ \\
Punish mate's infidelity threat & $-0.21^{* *}$ \\
Emotional manipulation & -0.05 \\
Commitment manipulation & -0.01 \\
Derogation of competitors & 0.02 \\
Resource display & $0.18^{* *}$ \\
Sexual inducements & 0.11 \\
Appearance enhancement & -0.02 \\
Love and care & -0.06 \\
Submission and debasement & 0.10 \\
Verbal possession signals & -0.08 \\
Physical possession signals & -0.08 \\
Possessive ornamentation & -0.06 \\
Derogation of mate & -0.03 \\
Intrasexual threats & $-0.13^{* *}$ \\
Violence against rivals & -0.10 \\
\hline
\end{tabular}

${ }^{*} p<0.05 ; * *^{*}<0.01$

sexual experiences. Chastity is espoused as an ideal supported by the notion that a woman who has been "easy," visiting covertly, and engaging in sexual behaviors would be more likely to be unfaithful in the future (however, vigilance and punish mate's infidelity threat, Table 2, were found to be negatively correlated with age). The belief that a premaritally sexually active woman might be more likely to cheat contributes to a sexual double standard and may inform mate retention practices. For example, even though there was no relationship between relationship status and mate retention scores found in this investigation (i.e., "in a relationship," "engaged," or "married"), those men who have sex with girlfriends may desire to remain in a relationship. However, women who are known to have premarital sex may be excluded from the marriage market by these same men.

Traditionally, people in Iran have had access to sex almost exclusively through marriage. Premarital relationships have not been common in Iran until recently but practices are beginning to change. In decades past, young men would very infrequently have had premarital sexual intercourse with girlfriends. The culturally accepted wisdom was that women needed their virginity to be eligible for marriage, so it was a man's duty not to pressure for sex in case the couple did not marry. A corollary practice of female virginity guarding, enforced by family members, was also more strictly adhered, e.g., vaginal penetration before marriage was taboo (intrasexual threats 
were also found to be negatively correlated with age, see Table 2). Also, although premarital sexual relationships are becoming more frequent, they are more common among a few upper-class people. These men also seem to prefer marrying girlfriends who were virgins when the relationship began.

According to WorldStat.info (http://en.worldstat.info) 2010 data from ITU World Telecommunication, $13 \%$ of Iranians use the internet (2010 data), and 91.3 per 100 inhabitants of Iran use mobile phones, a trend which is increasing and will bring more internet use as smartphones become more prevalent. Recent changes in relationship types and sexual attitudes are believed to be related to satellite, internet, and smart mobile phone usage in Iran which is exposing more Iranians to a wider array of Western relationship types and attitudes about sex.

The contraceptive prevalence is $57 \%$ overall in the Iranian population with $15 \%$ using contraceptive pills (United Nations 2014). Recent studies show that women are perceived as more attractive near ovulation (Cobey et al. 2013a; Haselton and Gildersleeve 2011; Miller et al. 2007) and that women report that their partners are more attentive and proprietary near ovulation (Gangestad et al. 2002; Haselton and Gangestad 2006). Cobey et al. (2012) found jealousy was significantly higher during the non-fertile phase of women's cycles. Additionally, pair-bonded women using hormonal contraceptives reported lower levels of intrasexual competition than when regularly cycling at either fertile or non-fertile cycle stages (Cobey et al. 2013b), presumably due to lowering the effects of contraceptive hormones on levels of cycling testosterone. One limitation of the present study is that the menstrual phases of fertility and non-fertility were not distinguished from each other; hence, it should be cautioned that this result only shows whether usage of contraceptive pills compared to non-usage has any relationship to Iranian women's reports of Iranian men's mate retention behavior. We found no effect on Iranian women's use of contraceptive pill and their partner's degree of mate retention in the sample. Further investigations in non-Western populations may reveal effects of hormonal contraceptives on women's behaviors where mate guarding is expressed differently than in Western countries (Pazhoohi and Burriss 2016; Pazhoohi and Hosseinchari 2014).

The major limitation of the current study is the lack of direct measures of testosterone from male participants. Further investigations would be appropriate to test circulating or salivary testosterone levels and their relationship to mate retention behavior performed by men and at what age.

In summary, the current study showed that the frequency of Iranian men's mate retention tactic use declines as they age. We also suggest that this trend is testosterone-dependent decline rather than women's youthfulness as there was no association between women's own age and their partners' use of mate retention tactics.

\section{References}

Abbasi-Shavazi, M., McDonald, P., \& Hosseini-Chavoshi, M. (2008). Modernization or cultural maintenance: the practice of consanguineous marriage in Iran. Journal of Biosocial Science, 40(06), 911-933.

Abbasi-Shavazi, M. J., Morgan, S. P., Hosseini-chavoshi, M., \& McDonald, P. (2009). Family change and continuity in Iran: birth control use before first pregnancy. Journal of Marriage and Family, 71(5), 1309-1324.

Aghajanian, A., \& Thompson, V. (2013). Recent divorce trend in Iran. Journal of Divorce and Remarriage, 54(2), 112-125.

Alvergne, A., Faurie, C., \& Raymond, M. (2009). Variation in testosterone levels and male reproductive effort: insight from a polygynous human population. Hormones and Behavior, 56(5), 491-497.

Barikani, A., Ebrahim, S. M., \& Navid, M. (2012). The cause of divorce among men and women referred to marriage and legal office in Qazvin, Iran. Global journal of health science, 4(5), 184-191.

Booth, A., Granger, D. A., Mazur, A., \& Kivlighan, K. T. (2006). Testosterone and social behavior. Social Forces, 85(1), 167-191.

Bremner, W. J., Vitiello, M. V., \& Prinz, P. N. (1983). Loss of circadian rhythmicity in blood testosterone levels with aging in normal men*. The Journal of Clinical Endocrinology and Metabolism, 56(6), $1278-1281$.

Bribiescas, R. G. (2006). On the evolution, life history, and proximate mechanisms of human male reproductive senescence. Evolutionary Anthropology, 15(4), 132.

Buss, D. M. (1989). Sex differences in human mate preferences: evolutionary hypotheses tested in 37 cultures. Behavioral and Brain Sciences, 12(01), 1-14.

Buss, D. M., \& Shackelford, T. K. (1997). From vigilance to violence: mate retention tactics in married couples. Journal of Personality and Social Psychology, 72(2), 346-361.

Buss, D. M., Shackelford, T. K., \& McKibbin, W. F. (2008). The mate retention inventory-short form (MRI-SF). Personality and Individual Differences, 44(1), 322-334.

Cobey, K. D., Buunk, A. P., Roberts, S. C., Klipping, C., Appels, N., Zimmerman, Y., et al. (2012). Reported jealousy differs as a function of menstrual cycle stage and contraceptive pill use: a within-subjects investigation. Evolution and Human Behavior, 33(4), 395-401.

Cobey, K. D., Buunk, A. P., Pollet, T. V., Klipping, C., \& Roberts, S. C. (2013a). Men perceive their female partners, and themselves, as more attractive around ovulation. Biological Psychology, 94(3), $513-516$

Cobey, K. D., Klipping, C., \& Buunk, A. P. (2013b). Hormonal contraceptive use lowers female intrasexual competition in pair-bonded women. Evolution and Human Behavior, 34(4), 294-298.

de La Rochebrochard, E., de Mouzon, J., Thépot, F., \& Thonneau, P. (2006). Fathers over 40 and increased failure to conceive: the lessons of in vitro fertilization in France. Fertility and Sterility, 85(5), $1420-1424$.

Dillon, L., Nowak, N., Shattuck, K., Weisfeld, G., Weisfeld, C., Imamoğlu, E., et al. (2014). When the cat's away, the spouse will play: a cross-cultural examination of mate guarding in married couples. Journal of Evolutionary Psychology, 12(2-4), 97-108.

Eisenegger, C., Haushofer, J., \& Fehr, E. (2011). The role of testosterone in social interaction. Trends in Cognitive Sciences, 15(6), 263-271.

Ellison, P. T. (2009). On fertile ground: A natural history of human reproduction: Harvard University Press.

Ellison, P. T., Bribiescas, R. G., Bentley, G. R., Campbell, B. C., Lipson, S. F., Panter-Brick, C., et al. (2002). Population variation in agerelated decline in male salivary testosterone. Human Reproduction, 17(12), 3251-3253.

Fales, M. R., Gildersleeve, K. A., \& Haselton, M. G. (2014). Exposure to perceived male rivals raises men's testosterone on fertile relative to 
nonfertile days of their partner's ovulatory cycle. Hormones and Behavior, 65(5), 454-460.

Feldman, H. A., Longcope, C., Derby, C. A., Johannes, C. B., Araujo, A. B., Coviello, A. D., et al. (2002). Age trends in the level of serum testosterone and other hormones in middle-aged men: longitudinal results from the Massachusetts male aging study. The Journal of Clinical Endocrinology and Metabolism, 87(2), 589-598.

Ferrini, R. L., \& Barrett-Connor, E. (1998). Sex hormones and age: a cross-sectional study of testosterone and estradiol and their bioavailable fractions in community-dwelling men. American Journal of Epidemiology, 147(8), 750-754.

Friedl, E. (1994). Source of female power in Iran. In M. Afkhami \& E. Friedl (Eds.), In the eye of the storm (pp. 67-151). NY: Syracuse University Press.

Fusani, L., Beani, L., Lupo, C., \& Dessi-Fulgheri, F. (1997). Sexually selected vigilance behaviour of the grey partridge is affected by plasma androgen levels. Animal Behaviour, 54(4), 1013-1018.

Gangestad, S. W., Thornhill, R., \& Garver, C. E. (2002). Changes in women's sexual interests and their partner's mate retention tactics across the menstrual cycle: evidence for shifting conflicts of interest. Proceedings of the Royal Society of London B: Biological Sciences, 269(1494), 975-982.

Goetz, A. T., Shackelford, T. K., Weekes-Shackelford, V. A., Euler, H. A., Hoier, S., Schmitt, D. P., et al. (2005). Mate retention, semen displacement, and human sperm competition: a preliminary investigation of tactics to prevent and correct female infidelity. Personality and Individual Differences, 38(4), 749-763.

Harman, S. M., Metter, E. J., Tobin, J. D., Pearson, J., \& Blackman, M. R. (2001). Longitudinal effects of aging on serum total and free testosterone levels in healthy men. The Journal of Clinical Endocrinology and Metabolism, 86(2), 724-731.

Haselton, M. G., \& Gangestad, S. W. (2006). Conditional expression of women's desires and men's mate guarding across the ovulatory cycle. Hormones and Behavior, 49(4), 509-518.

Haselton, M. G., \& Gildersleeve, K. (2011). Can men detect ovulation? Current Directions in Psychological Science, 20(2), 87-92.

Iran Statistical Center. (2015). Iran Statistical Yearbook of 1392 (March 2013-March 2014). Presidency, Management and Planning Organization, Statistical Centre of Iran. Retrieved from www.amar.org.ir/english/ January 2016.

Jones, D. (1995). Sexual selection, physical attractiveness, and facial neoteny: cross-cultural evidence and implications. Current anthropology, 723-748.

Kenrick, D. T., \& Keefe, R. C. (1992). Age preferences in mates reflect sex differences in human reproductive strategies. Behavioral and Brain Sciences, 15(01), 75-91.

Marcinkowska, U. M., Dixson, B. J., Kozlov, M. V., Rantala, M. J. (2015). Men's preferences for female facial femininity decline with age. The Journals of Gerontology Series B: Psychological Sciences and Social Sciences, 00(00):1-7.

Mathes, E. W., Brennan, S. M., Haugen, P. M., \& Rice, H. B. (1985). Ratings of physical attractiveness as a function of age. The Journal of Social Psychology, 125(2), 157-168.

McDonald, P. (1994). Families in developing countries: idealized morality in the Asian family. In L.-J. Cho \& M. Yada (Eds.), Transition and change in the Asian family (pp. 19-28). Honolulu: East-west Center.

Miller, G., Tybur, J. M., \& Jordan, B. D. (2007). Ovulatory cycle effects on tip earnings by lap dancers: economic evidence for human estrus?ẫ ${ }^{\sim}$ Evolution and Human Behavior, 28(6), 375-381.
Muehlenbein, M. P., \& Flinn, M. V. (2011). Patterns and processes of human life history evolution. Oxford handbook of life history, 153-168.

Nahoul, K., \& Roger, M. (1990). Age-related decline of plasma bioavailable testosterone in adult men. Journal of Steroid Biochemistry, 35(2), 293-299.

Pazhoohi, F., \& Burriss, R. P. (2016). Hijab and "Hitchhiking": A field study. Evolutionary Psychological Science, 2(1), 32-37.

Pazhoohi, F., \& Hosseinchari, M. (2014). Effects of religious veiling on Muslim men's attractiveness ratings of Muslim women. Archives of Sexual Behavior, 43(6), 1083-1086.

Perrett, D. I., Lee, K. J., Penton-Voak, I., Rowland, D., Yoshikawa, S., Burt, D. M., et al. (1998). Effects of sexual dimorphism on facial attractiveness. Nature, 394(6696), 884-887.

Plas, E., Berger, P., Hermann, M., \& Pflüger, H. (2000). Effects of aging on male fertility? Experimental Gerontology, 35(5), 543-551.

Puts, D. A. (2010). Beauty and the beast: mechanisms of sexual selection in humans. Evolution and Human Behavior, 31(3), 157-175.

Puts, D. A., Barndt, J. L., Welling, L. L. M., Dawood, K., \& Burriss, R. P. (2011). Intrasexual competition among women: vocal femininity affects perceptions of attractiveness and flirtatiousness. Personality and Individual Differences, 50(1), 111-115.

Romero-Martínez, A., González-Bono, E., Lila, M., \& Moya-Albiol, L. (2013a). Testosterone/cortisol ratio in response to acute stress: a possible marker of risk for marital violence. Social Neuroscience, $8(3), 240-247$.

Romero-Martínez, Á., Lila, M., Sariñana-González, P., González-Bono, E., \& Moya-Albiol, L. (2013b). High testosterone levels and sensitivity to acute stress in perpetrators of domestic violence with low cognitive flexibility and impairments in their emotional decoding process: a preliminary study. Aggressive Behavior, 39(5), 355-369.

Schiavi, R. C., Schreiner-Engel, P., White, D., \& Mandeli, J. (1991). The relationship between pituitary-gonadal function and sexual behavior in healthy aging men. Psychosomatic Medicine, 53(4), 363-374.

Shackelford, T. K., Voracek, M., Schmitt, D. P., Buss, D. M., WeekesShackelford, V. A., \& Michalski, R. L. (2004). Romantic jealousy in early adulthood and in later life. Human Nature, 15(3), 283-300.

Shackelford, T. K., Goetz, A. T., \& Buss, D. M. (2005). Mate retention in marriage: further evidence of the reliability of the Mate Retention Inventory. Personality and Individual Differences, 39(2), 415-425.

Symons, D. (1979). The evolution of human sexuality. Oxford: Oxford Univ. Press.

Torabi, F., \& Baschieri, A. (2010). Ethnic differences in transition to first marriage in Iran: the role of marriage market, women's socioeconomic status, and process of development: Max Planck institute for demographic research.

Tsitouras, P. D., Martin, C. E., \& Harman, S. M. (1982). Relationship of serum testosterone to sexual activity in healthy elderly men. Journal of Gerontology, 37(3), 288-293.

Uchida, A., Bribiescas, R. G., Ellison, P. T., Kanamori, M., Ando, J., Hirose, N., et al. (2006). Age related variation of salivary testosterone values in healthy Japanese males. The Aging Male, 9(4), 207-213.

United Nations (2014). Department of Economic and Social Affairs, Population Division. World Contraceptive Use 2014.

Welling, L. L. M., Jones, B. C., DeBruine, L. M., Smith, F. G., Feinberg, D. R., Little, A. C., et al. (2008). Men report stronger attraction to femininity in women's faces when their testosterone levels are high. Hormones and Behavior, 54(5), 703-708.

Wirth, M. M., \& Schultheiss, O. C. (2007). Basal testosterone moderates responses to anger faces in humans. Physiology \& Behavior, 90(2), 496-505. 